\title{
APUNTES SOBRE ESTACIONALIDAD Y SUBSISTENCIA DE LOS GRUPOS HUMANOS DEL CANTÁBRICO OCCIDENTAL EN TORNO AL 13000 BP
}

\author{
NOTES ON SEASONALITY AND SUBSISTENCE OF WEST CANTABRIAN HUMAN \\ GROUPS ABOUT 13000 BP
}

ANA MATEOS CACHORRO $(*)$

\section{RESUMEN}

Las paleocomunidades del Pleistoceno final desarrollaron unas respuestas de adaptación al entorno para paliar alguna de sus constricciones ambientales. Una de ellas, en lo que a técnicas de caza se refiere, era la selección diferencial de algunos individuos bien por edad o sexo. En este estudio se analizan las posibles edades de muerte estimadas a partir de las mandíbulas y el procesado antrópico de las mismas por parte de los grupos humanos que habitaron la Cueva de Las Caldas en el 13000 BP. Con ello se trata de caracterizar los patrones de mortalidad de los ungulados que formaron parte de su dieta, definir el carácter estacionario del yacimiento y comprobar si se puede hablar de una táctica de planificación temporal intencionada y diferencial como respuesta a una estrategia de subsistencia. Estos planteamientos forman parte del sistema paleoeconómico responsable del funcionamiento de estas sociedades del Paleolítico Superior Final ante las presiones ecológicas y limitaciones culturales que les eran impuestas. Este análisis quizá nos permita además aproximarnos a sus modos de ocupación y movilidad en un territorio como espacio estratégico de gestión de recursos.

\begin{abstract}
Final Pleistocene palaeocommunities developed some adaptative answers to alleviate their environmental constrictions. One of them using in hunting strategies was the differential selection of some individuals by age or sex. In this study the possible ages of death are estimated from mandibles and analysed along with their processing by the human
\end{abstract}

(*) Dpto. Prehistoria, Historia Antigua y Arqueología. Universidad de Salamanca. Cervantes s/n. 37002 Salamanca. Correo electrónico: anamat@usal.es

Recibido: 9-I-02; aceptado: 20-V-02. groups that lived in Caldas Cave about 13000 BP. It will try to characterize mortality patterns from the ungulates in their diet, to define the stationary character of the site and to check if it is possible to consider a tactics of intentional and differential temporal planning as an answer to a subsistence strategy. These are part of a palaeoeconomic system that organized the life of these Final Upper Palaeolithic societies in face of the ecological pressures and cultural limitations that were imposed them. This analysis may allow us to estimate modes of occupation and mobility in a territory as a strategic space of resource management.

Palabras clave: Cueva de Las Caldas. Magdaleniense medio. Región cantábrica. Subsistencia. Estacionalidad. Perfiles de mortalidad. Zooarqueología.

Key words: Caldas Cave. Middle magdalenian. Cantabrian area. Subsistence. Seasonality. Mortality profiles. Zooarchaeology.

\section{INTRODUCCIÓN}

Antes de abordar la problemática inherente al estudio de los patrones de mortalidad que se pretende, vamos a intentar ver qué significa la estacionalidad, su concepto, significado y alcance, en definitiva, cual es su potencial interpretativo en Arqueología. Fue el investigador Monks quien reconoció para la investigación arqueológica los estudios de estacionalidad, definiendo el término como la coincidencia temporal de una actividad cultural o económica con eventos naturales (Monks 1981; Pike-Tay 1991b: 20). El estudio de las curvas de mortalidad ofrece uno de los mejores medios para aproximarse a los modos de adquisición de presas y las técnicas de caza e inferir probables periodos de 
ocupación, aunque su interpretación está sujeta actualmente a problemas metodológicos.

Los cálculos de edad de los individuos son convenientes para establecer las pautas de cómo era la comunidad animal (biotopo) que existía, así como para aproximarnos a la subsistencia de los grupos humanos que compartían ese nicho ecológico. El conocimiento del comportamiento de las presas potenciales es determinante para conocer los comportamientos de los grupos humanos del Paleolítico y la posibilidad de determinar la estación y edad de muerte contribuye a la reconstrucción del sistema de hábitats y de la subsistencia. La extrapolación de estos datos nos aporta la posibilidad de considerar sus patrones ocupacionales, y por ende, la visión de sus espacios estratégicos de gestión del territorio y recursos (1).

\subsection{La estacionalidad, límites y procedimientos}

Los perfiles arqueológicos de muerte son el resultado de variables (además de la edad de muerte) que interactúan entre ellas: la dinámica de las poblaciones de presa, los métodos de caza, las decisiones de transporte, los agentes tafonómicos, etc..., que no pueden ser previstos (Costamagno 2000; Lubinski 2001). Estos han sido usados en Paleobiología y Arqueología para comparar perfiles de un conjunto dado con otro teórico y generalizado (Klein 1979; Levine 1983; Lyman 1987; Stiner 1991). Para estimar la estacionalidad de un yacimiento o de las actividades humanas que allí tuvieron lugar, existen varios métodos. Aún hoy, muchos de ellos están en revisión y crítica (2) (Bourque et al. 1978; Brugal y David 1993; Davidson 1976; Enloe 1997; Gordon 1993; Lubinski y O’Brien 2001; Monks 1981; Monks y Johnston 1993; Spiess 1995).

Se han catalogado como procedimientos indirectos y directos. Los primeros infieren la estacionalidad a través de los datos arqueológicos además de los datos extraídos de la flora y la fauna, y añaden datos de la morfogénesis deposicional y la dinámica

(1) Vid. C. Díez Fernández-Lomana y A. Mateos Cachorro, (en prep.): Estudio de los patrones de mortalidad y edades de muerte en dientes de herbivoros para una aproximación a las épocas de ocupación y estacionalidad de los grupos humanos del Pleistoceno Inferior y Medio en la Sierra de Atapuerca (Burgos).

(2) Vid. H. Martin, 1994: Nouveaux milieux, nouveaux chasseurs: une approche des comportements au post-glaciaire à travers l'étude des saisons de capture du gibier. Thèse de Doctorat Inédite. Université de Toulouse-le-Mirail, 300 pp. En páginas 5-40 para una revisión de los estudios de estacionalidad aplicados a la Prehistoria.

T. P., 59, n. $^{\circ} 2,2002$ sedimentaria del depósito, estimaciones del tamaño de la población, patrones y localización del asentamiento, patrones de enterramiento y factores postdeposicionales, así como análisis funcionales de los conjuntos líticos. Por contra, los sistemas de inferencia directa se concretan en varios métodos para el registro óseo:

\section{a) Presencia o ausencia de especies faunísticas}

Es el método más ampliamente utilizado aunque requiere unos conocimientos previos de la etología y biología de los grupos animales representados para establecer los perfiles de comportamiento estacional de las especies identificadas en los yacimientos (adaptaciones eco-etológicas: regimen alimentario, distribución de recursos, reproducción, movimientos migratorios y composición de grupos). Ha de usarse con cautela, porque en la presencia/ausencia de una especie en un yacimiento intervienen además de la acción y selección antrópica otros factores añadidos como son las alteraciones tafonómicas, la conservación y el transporte diferencial.

\section{b) Estructura de la población faunística}

Se basa en el hecho de que la composición por edades y sexos varía estacionalmente en muchas especies. Este metodo es bastante problemático a la hora de establecer el tamaño y perfiles de edad de esas poblaciones porque, como vimos anteriormente, en la acumulación de estos restos y su representación de frecuencias influyen factores tafonómicos como la preservación diferencial, acorde a las densidades óseas, y otros de índole cultural o paleoeconómica (David y Enloe 1992; Guillien y Martin 1968; Julien 1989). Con todo, el análisis de la determinación de edades mediante procesos fisiológicos como la fusión epifisaria, la abrasión dental y el crecimiento de las coronas exige muestras lo suficientemente amplias para establecer el ritmo temporal de estas variaciones.

\section{c) Eventos fisiológicos de carácter temporal: crecimiento de las astas, indicadores de estrés biológico, huesos medulares}

El crecimiento estacional de las astas en los cérvidos ocurre en todos los individuos machos excep- 
to en el género Rangifer, en el que ambos sexos poseen cornamenta. Esta se desarrolla a un ritmo anual: creciendo en primavera, y mudando después de la época de celo, en otoño, aunque en los más jóvenes y en los machos más viejos permanece hasta la primavera sin caerse. En el caso de las hembras Rangifer, sus astas mudan después del nacimiento de las crías. Este es un ejemplo que denota que el margen de crecimiento y caída del asta es bastante amplio y varía inter e intraespecíficamente como para establecer con certeza una interpretación estacional concreta a partir de la recogida, por ejemplo, de un montón de astas de muda y de astas soldadas al cráneo en un yacimiento (Billamboz 1979; Goss 1983).

Los indicadores de estrés, como las líneas de Harris en los huesos largos de los mamíferos y las hipoplasias del esmalte dental, pueden ser de gran utilidad siempre que estemos hablando de sucesos que ocurren en muy corto espacio temporal. Existen otros sucesos como las variaciones en los huesos medulares de las aves (Rick 1975), que ocurren como estrategia reproductiva en las hembras para acumular minerales en la producción del cascarón de los huevos antes del anidamiento. Tiene la dificultad de que hay que establecer la duración de la época de apareamiento de cada especie.

Por último, podemos considerar los ritmos y ocurrencias cíclicas de estrés biológico de movilización de grasa en los ungulados (3). La grasa de los huesos se localiza dentro de la estructura del propio hueso en la producción de ácidos grasos y, químicamente, difiere un poco de los depósitos de grasa o tuétano de las cavidades medulares, y como ellos, varía en respuesta a factores tales como la dieta, la salud, época del año, sexo, estado reproductivo y edad (Mateos 1999, 2000, 2002).

\section{d) Análisis de estructuras crecientes o de incremento (esqueleto-cronología)}

En lo que respecta a moluscos y peces, son métodos válidos para determinar la explotación de estos recursos marinos (4). Existen otros elementos

(3) Vid. A. Mateos Cachorro: Estudio de la fragmentación de falanges y mandíbulas en la secuencia temporal del 19000-13000 BP de la Cueva de Las Caldas (Priorio, Oviedo). Implicaciones paleoeconómicas: nutrición y subsistencia. Memoria de Grado. Inédita. Dpto. Prehistoria, Historia Antigua y Arqueología. Universidad de Salamanca, 1999, $353 \mathrm{pp}$.

(4) Vid. Le Gall y Martin 1996 para los criterios de estacionalidad por análisis de ictiofaunas. anatómicos de crecimiento estacional además de los pedicelos del asta en los cérvidos, como la presencia de depósitos anuales en los huesos y en los dientes de mamíferos (Pike-Tay 1991a: 32-42, 1991b, 1995; Pike-Tay y Knecht 1993). En estos últimos, los anillos dentales se observan microscópicamente en las deposiciones de cemento (cemento-cronología) en el exterior de las raíces y en la dentina. Así, la opacidad y la espesura de la última banda depositada nos confirmará la época de muerte. Han sido muchos los biólogos que han empleado este procedimiento para estudiar las estructuras de edad en poblaciones animales actuales (Aitken 1975; Beasley et al. 1992; Debeljak 1996; Gordon 1993; Grue y Jensen 1979; Jones y Boyde 1974; Keiss 1969; Klevezal y Pucek 1987; Liebermann y Meadow 1992; Lieberman et al. 1990; Low y Cowan 1963; Lowe 1967; Mitchell 1963; Novakowski 1965; Pailhaugue 1998a; Spinage 1976; Stallibrass 1982).

El estudio de este fenómeno aplicado a la Arqueología se ha visto ampliado en los últimos treinta años (5) (Bourque et al. 1978; Burke 1993; Burke y Castanet 1995; Gordon 1988; Kay 1974; Koike y Ohtaishi 1985; Le Gall y Martin 1996; Martin 1995; Martin y Le Gall 1989; Olsen 1989; Pike-Tay 1991, 1993, 1995,1998; Spiess 1979, 1995).

Muy recientemente, en Francia estos estudios sobre cemento dentario en materiales arqueológicos están cobrando auge (Griggo y Pubert 1999). En los yacimientos peninsulares hay alguna aplicación de esta técnica, aunque escasa y tímida, cuyos resultados son para tener en cuenta (Pérez Ripoll et al. 2001; Pike-Tay et al. 1999). No obstante, dado el carácter destructivo de la técnica, las dificultades en la preparación de muestras, la necesidad de disponer de una muestra de referencia actual amplia, unido al desconocimiento de los factores que regulan la formación de los depósitos, muchos arqueólogos se muestran reticentes a utilizar esta analítica.

Otros investigadores emplean técnicas de radiografía sobre mandíbulas (Brown y Chapman 1990, 1991; Carter 1998), analizando los estadios de de-

(5) En su magnífico estudio de las estrategias de caza en Solutré, Sandra L. Olsen estableció que los ciervos probablemente fuesen cazados en invierno y primavera, mientras que los caballos en la época que transcurre desde la primavera al otoño, con una gran concentración de batidas en los meses de verano. Examinó una muestra de 75 molares de Equus de los que 30 fueron seccionados según el método de análisis del cemento, resultando 21 de ellos con la banda final depositada en verano (Olsen 1989: 302$303)$. 
sarrollo en los subadultos pues consideran que este método ofrece mejor resolución de edad para establecer la época de muerte. Un último apunte sobre estimaciones de edad es la que ofrece la técnica de la medición de la dimensión dental. En esta analítica hay que asumir desde el inicio que la ratio de reducción de la altura de la corona es constante durante la vida del diente y que esta relación es aproximadamente lineal (Klein 1982; Klein et al. 1981, 1983). Este parámetro es un imperfecto estimador de edad individual, pero válido para producir un perfil de edad interpretable (Gifford 1991a y b; Morrison y Whitridge 1997; Spinage 1976) y acaso sugerir estacionalidad cuando encontramos discontinuidades en dichos perfiles.

Con todo lo expuesto anteriormente, es requisito indispensable en cualquier estudio zooarqueológico, examinar de cerca los parámetros de población de las especies cazadas, para ver algunas consideraciones estratégicas en los patrones de explotación de los taxones (selección por edad y sexo) (6), la estacionalidad y sus implicaciones en los momentos de ocupación de un yacimiento (Blasco Sancho 1995, 1997; Pailhaugue 1998b; Pike-Tay et al. 1999) (7).

\section{MATERIAL}

En este estudio se ha intentado analizar las posibles edades de muerte estimadas a partir de las mandíbulas (8) y el procesado antrópico de las mis-

(6) M.C. Stiner (1994: 332-351) trata las cuestiones de estacionalidad bajo tres perspectivas: una la focaliza en los patrones de muerte de ungulados juveniles, basándose en las secuencias de erupción-desgaste de los premolares deciduales; en segundo lugar, en el desarrollo de las astas: en ciclos de crecimiento y caída en ciervos, gamos y corzos modernos (también válido para ver la ratio macho/hembra); y en tercer lugar, en la determinación de la sex ratio de adultos mediante las frecuencias de pearl teeth (caninos superiores).

(7) Para muchos investigadores, entre ellos James G. Enloe (1997), los mejores indicadores de estacionalidad son los rasgos de erupción y los de desgaste tanto en la dentición permanente como en la decidual. Por el contrario, otros como Davidson (1989: 223-225) opinan que el análisis del grado de desgaste de los dientes no proporciona datos suficientemente detallados sobre la estación en que murió el animal, porque existen variaciones importantes de desgaste entre machos y hembras, en función del tipo de alimentación y el estado de nutrición de estos animales. Sin embargo, este último investigador afirma que se puede obtener alguna información a partir de la presencia de animales jóvenes y extraer ciertos datos de la deposición de las capas de cemento, aunque se necesitan series muy amplias.

(8) Aún continúan en curso los análisis para la construcción de perfiles de mortalidad combinando métodos cuantitativos de dimensión dental incluyendo las piezas dentarias aisladas que, sin mas por parte de los grupos humanos que habitaron la Cueva de Las Caldas en el 13000 BP.

Estas paleocomunidades del Pleistoceno final desarrollaron unas respuestas de adaptación al entorno para paliar alguna de sus constricciones ambientales. Una de ellas en lo que a técnicas de caza se refiere era la selección diferencial de algunos individuos bien por edad o sexo, de ahí la caracterización de los patrones de mortalidad de los ungulados que formaron parte de su dieta. Intentamos con ello definir el carácter estacionario del yacimiento y comprobar si se puede hablar de una táctica de planificación temporal intencionada y diferencial como respuesta a una estrategia de subsistencia; aproximarnos a sus tácticas de selección específica (cohortes de edad y sexo preferentes, ecotipos y especies dominantes recuperadas), planificación temporal (estudio de los ritmos estacionales de explotación, de la distribución estacional de las temporadas de caza o por el contrario verificar un continuo de actividad en el transcurso del año), y, por último, a las técnicas de procesado y grado de intervención antrópica para establecer los posibles ritmos de tratamiento de las carcasas (Corchón y Mateos, e.p.).

A pesar de la problemática esbozada en el empleo de cada uno de los métodos de estimación de edad y sus limitaciones evidentes ante muestras fósiles, nuestros intereses más inmediatos se han focalizado en establecer una probable estacionalidad a partir de los individuos inmaduros, una vez establecido un perfil de mortalidad mediante las secuencias de erupción dentaria y las tablas de desgaste y uso de la muestra estudiada. La elección de este procedimiento para la construcción de edades de muerte responde al carácter de ensayo preliminar de estos análisis, a la espera del estudio integral del material óseo recuperado y conservado en el nivel VIII, en el que se incluyen y combinan otros estimadores de edad no destructivos sobre dientes, como la dimensión dental de muchas piezas aisladas y el estudio de los desarrollos dentarios alveolares y radiculares mediante radiografías. No se contempla, por el momento, el empleo de técnicas destructivas de cementocronología a traves de laminados y secciones de la dentición.

duda, ampliaran numéricamente la muestra y enriquecerán las estimaciones de edades de muerte para los taxones representados en este nivel. De igual modo, se valora la posibilidad de abordar un estudio complementario de estacionalidad empleando además de dentición, otros restos esqueléticos conservados como indicadores: cuernas y la presencia de salmones. 


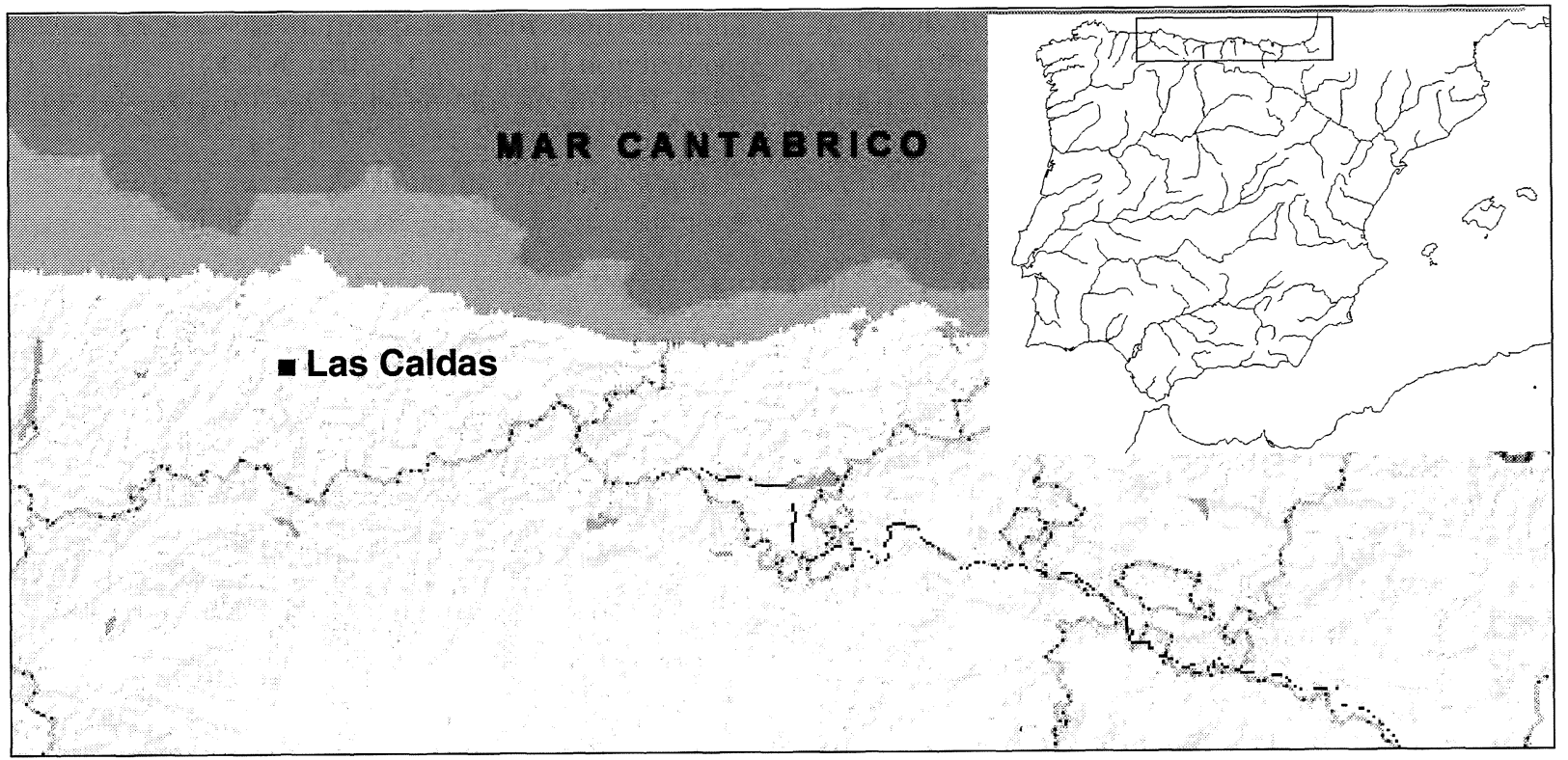

Fig. 1. Localización de la Cueva de Las Caldas (Priorio, Oviedo).

\subsection{Situación y contexto arqueológico}

La cueva de Las Caldas se sitúa en el término municipal de San Juan de Priorio, a 1200 m. de la localidad de Las Caldas, y a unos $8 \mathrm{kms}$ de Oviedo. Su entrada, orientada al O-SO se abre en la vertiente izquierda de un pequeño valle lateral por el que discurre el arroyo de Las Caldas, que vierte sus aguas al Nalón, a unos $2 \mathrm{kms}$ de la cueva. Sus coordenadas geográficas son: $2^{\circ} 14^{\prime} 05^{\prime \prime}$ de longitud E y $43^{\circ} 20^{\prime} 10^{\prime \prime}$ de latitud $\mathrm{N}$, a una altura de $160 \mathrm{~m}$ sobre el nivel del mar (Fig. 1).

Este yacimiento ha proporcionado una de las secuencias estratigráficas más extensas para estos momentos tardiglaciares, y cuenta con una serie amplia y coherente de dataciones (23), que podría precisar y matizar las cronologías paleoclimáticas y horizontes culturales propuestos para el Cantábrico (Corchón 1990, 1992, 1995a, 1995b, 1996, 1999; Corchón et al. 1981; Fortea et al. 1990)

Para este análisis hemos seleccionado, a modo de muestreo, uno de los niveles arqueológicos más ricos, el nivel VIII, bien definido en la secuencia cronoestratigráfica de la cueva, como perteneciente al horizonte cultural del Magdaleniense medio antiguo (13 640 \pm 150 BP) (Jordá et al. 1982; Corchón 1996, 2000) con un área total excavada de unos $7 \mathrm{~m}^{2}$.

Aunque la morfogénesis deposicional y la dinámica sedimentaria todavía se encuentran en curso de investigación, el análisis intraespacial y la representatividad anatómica específica cuentan con limitaciones añadidas por las condiciones del depósito (duración, ocupación y abandono), y sobre todo, por las alteraciones tafonómicas y factores postdeposicionales (conservación diferencial, erosión, removilización, etc.) que explican la dinámica de génesis de esta acumulación.

\section{MÉTODOS}

\subsection{Cuantificación: datos globales}

En el análisis integral de los yacimientos ha de incluirse el informe faunístico correspondiente, aunque éste no está exento de limitaciones (Meltzer et al. 1992). El no reconocerlas puede inducir a cometer errores interpretativos que lesionen la argumentación teórica. Las limitaciones de los datos (el carácter de la excavación, los procesos tafonómicos, el tamaño de la muestra y los propios límites del investigador) restringen la aplicación de ciertas metodologías y restan capacidad informativa a los restos. Conocer las limitaciones de los datos que se manejan, y su propia capacidad explicativa, incide en la fiabilidad interpretativa de los mismos.

Además, el tamaño de la muestra, el $n$, es relevante a la hora de las estimaciones oportunas que se 
establezcan a partir de ellos. Por debajo de ciertos valores críticos, el tamaño de la muestra puede distorsionar la representatividad original de la misma o infravalorar ciertos parámetros.

En el análisis cuantitativo de nuestros restos óseos hemos tomado algunas de las unidades de cuantificación más básicas en Zooarqueología, como son el NMI (Número Mínimo de Individuos), el NME (Número Mínimo de Elementos) y NISP (Número de Especímenes Identificados), así como los recuentos de NR (Número de Restos). Estos llamados estimadores de abundancia no son medidas perfectamente válidas, pero dan una imagen aproximada del conjunto óseo.

Con todo, son las herramientas de estimación más extendidas entre todos los investigadores, que con más o menos precisión nos acercan a las características de la formación ósea (Brugal et al. 1994; Ducos 1975, 1984; Grayson 1979, 1984; Lyman 1994a, 1994b; Poplin 1976, 1977, 1981; Valente 1997).

Existen muchas contradicciones en la definición (9) y cálculo de estas variables, de ahí que con esa problemática, nos veamos indefectiblemente avocados a delimitar nuestros parametros, recuentos y criterios de cálculo de estas variables cuantitativas. La primera y más básica unidad de recuento es el Número de Restos (NR), o más concretamente el Número Total de Restos (NRT):

$$
\mathrm{NRT}=\mathrm{ND}+\mathrm{NRDa}+\mathrm{NRDt}
$$

donde $\mathrm{ND}=$ restos indeterminados o no determinables (10) NRDa = restos identificados anatómicamente, sin indicación taxonómica, y NRDt = restos determinados anatómica y taxonómicamente.

Le sigue en el orden lógico de cálculo, el Número de Especímenes Identificados (NISP), el Número Mínimo de Elementos (NME), es decir, el mínimo número de elementos o porciones anatómicas, sea cual sea la edad, sexo o lateralidad, para contabilizar todos los especímenes observados (la estimación del número mínimo para una categoría anatómica designada). Para establecer el NME, se ha considerado en las mandíbulas, el fragmento de la rama horizontal con serie dental conservada.

(9) Vid. Lyman 1994a, en el que compila 112 términos cuantitativos con 122 definiciones.

(10) Se ha de determinar el criterio de consideración, que en este caso son todas las esquirlas $<2 \mathrm{~cm}$.
La unidad cuantitativa más frecuente es el Número Mínimo de Individuos (NMI), es decir, el número de animales/individuos necesario para englobar a todos los especímenes identificados. Es conveniente señalar la problemática generada y las críticas vertidas sobre esta unidad, ya que existe numerosa bibliografía al respecto sobre estas cuestiones (Castaños 1984; Casteel 1977; Horton 1984; Poplin 1976) (11). Para nuestros análisis de abundancia, tomaremos el NMI calculado como NMIf (Número Mínimo de Frecuencia), sobre el elemento anatómico mandíbula, siempre que estén presentes como mínimo dos piezas dentarias, ya sean deciduales o permanentes (12), y siempre lateralizadas, sin tener en cuenta ni la edad ni el sexo de los taxones.

\subsection{Estimación de la edad: perfiles de mortalidad}

Con ayuda de los cuadros de emergencia y desgaste dentario para las series dentales en mandíbulas se han establecido unas cohortes o grupos de edad básicos (edades relativas de desarrollo dental). Siendo un modelo cualitativo, está sometido a algunas variaciones en las tasas de remplazo, y sobre todo, en las desgaste y uso debido, en parte, a la estabilidad ecológica propia de las poblaciones animales; aun con esa limitación, estas variables han sido y son las más utilizadas para estimar edades en muestras zooarqueológicas, pero su uso queda restringido a los mamíferos (Tab. 1) (13). Hablamos en erupción de desarrollos dentales y para desgaste hablamos de edades funcionales (patrones de desgaste en dentina y cemento expuesto en la superficie oclusal). Cuando la serie dental para analizar contiene muchos permanentes, el método se basa en una evaluación más o menos subjetiva del uso, una vez determinados los momentos de erupción y reemplazo de dientes lacteales y definitivos.

(11) Por citar a algunos de sus detractores, (vid. Ducos 1975, 1984), que rechaza la validez de NMI; Gautier (1984) afirma que es desproporcionado respecto al número original de animales por tanatocenosis, y Grayson (1979) no toma el NMI como un valor absoluto y sí como una escala de observación ordinal de abundancias faunísticas.

(12) Teniendo en cuenta que el valor de la representación de individuos está infravalorado, porque no se han tenido en cuenta los dientes aislados, que posiblemente aumentarían el número mínimo.

(13) Vid. P. Fosse: Taphonomie Paléolithique: les grands ma mmifères de Soleilhac (Haute-Loire) et de Lunel-Viel 1 (Hérault). Thèse de Doctorat Inédite. Université de Provence-Aix-Marseille I. $1994,257 \mathrm{pp}$ 


\begin{tabular}{|l|l|l|}
\hline \multicolumn{1}{|c|}{$\begin{array}{c}\text { Grupo } \\
\text { taxonómico/Taxón }\end{array}$} & \multicolumn{1}{c|}{ ERUPCIÓN* } & \multicolumn{1}{c|}{ DESGASTE } \\
\hline Ungulados & $\begin{array}{l}\text { Hillson 1986: 201-230 } \\
\text { Stiner 1994: 335 }\end{array}$ & Hillson 1986 \\
\hline $\begin{array}{l}\text { Cervidae } \\
\text { (Cervus elaphus) }\end{array}$ & $\begin{array}{l}\text { Fosse 1994** } \\
\text { Spiess 1979 } \\
\text { Varin 1980 } \\
\text { West 1997 }\end{array}$ & $\begin{array}{l}\text { Fosse 1994 } \\
\text { Mariezkurrena 1983 } \\
\text { Varin 1980 }\end{array}$ \\
\hline Capreolus & Varin 1980 & $\begin{array}{l}\text { Aitken 1975 } \\
\text { Varin 1980 }\end{array}$ \\
\hline Caprinae & Silver 1969 & Grant 1982 \\
\hline Rupicapra & $\begin{array}{l}\text { Pailhaugue 1998 } \\
\text { Pérez Barbería 1994 }\end{array}$ & $\begin{array}{l}\text { Pailhaugue 1998 } \\
\text { Pérez Barbería 1994 }\end{array}$ \\
\hline Equus & Levine 1982 & $\begin{array}{l}\text { Levine 1982 } \\
\text { Morales 1988 }\end{array}$ \\
\hline Canidae & Stiner 1994: 323 & $\begin{array}{l}\text { Silver 1969 } \\
\text { Stiner 1994 }\end{array}$ \\
\hline Carnívoros & $\begin{array}{l}\text { Hillson 1986 } \\
\text { Stiner 1994: 321 }\end{array}$ & $\begin{array}{l}\text { Hillson 1986 } \\
\text { Stiner 1994: 320-327 }\end{array}$ \\
\hline
\end{tabular}

Tab. 1. Datos de emergencia y desgaste dental empleados en nuestro estudio.

* para deciduos y permanentes.

** recoge los métodos y clases de edad de Habermehl 1961, Lowe 1967, Varin 1980, Briot y Voilquin 1986.

No olvidemos que intentamos aproximarnos a la probable edad de muerte o abatimiento del individuo, aunque en ocasiones sea imposible precisar los meses o años del fósil, y haya que adscribirlo a los estadios de edad generales que se han establecido, tomando en consideración las llamadas edades críticas (14), aquellas en las que el animal está en proceso de cambio. Las fechas concretas se establecen basándose en infantiles sólo con dentición lacteal, juveniles, con mezcla de lacteales y definitivos y adultos con dientes definitivos. Así para estimaciones sobre dentición tendremos:

- Infantil: los lactantes y primales, aproximadamente hasta 1-2 años.

- Juvenil: incluye a los individuos entre 1-2 y 3 años, aproximadamente.

- Adulto: a partir de 3-4 años.

- Indeterminado: aquellos restos en los que ha sido imposible establecer cualquier valoración de edad.

Estos grupos de edad considerados a priori, llevan implícito el conocimiento de la edad estimada para la erupción del primer diente definitivo, el M1: en Cervidae hacia los 6 meses (West 1997); en Caprinae, entre los 3-6 meses; en Equidae alrededor de los 12 meses, y en Canidae, en torno a los 35 meses. Para discriminar la cohorte de adultos, hemos de tener conocimiento de la edad a la que emerge el último diente, que suelen ser los premolares definitivos, P3-P4: en Cervus, la secuencia

(14) Estas edades con frecuencia varían entre especies debido a sus diferentes ritmos y ciclos reproductivos de la dinámica de poblaciones.

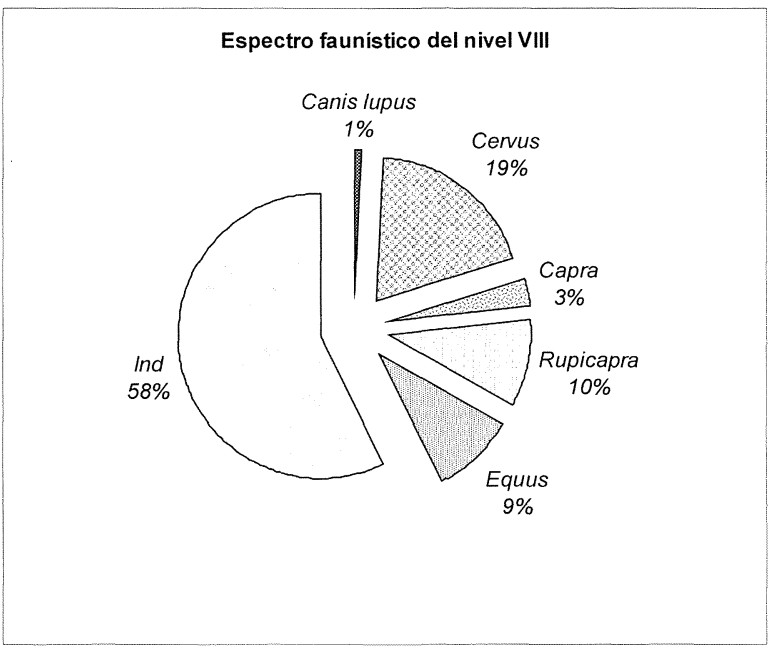

Fig. 2. Espectro faunístico reconocido a partir de mandíbulas.

dp3-P3 hacia los 23-27 meses, para Capra, la secuencia dp4-P4 en torno a los 24 meses; en Equus, el dp3-P3 aproximadamente a los 36 meses, y por último, para Canidae, la serie dp-P2,P3 hacia los 56 meses (Stiner 1994).

Para los especímenes adultos, se ha considerado la presencia del M3 (pieza dentaria de tardía emergencia), mientras que para los inmaduros, se tuvo en cuenta la dentición decidual todavía presente, con algún signo leve de desgaste.

\section{ANÁLISIS DE DATOS}

\subsection{Espectro faunístico y datos de abundancia}

En datos globales, los taxones reconocidos son, en su mayoría ungulados, y una única representación de carnívoros. Entre las especies determinadas nos encontramos con: Cervidae: Cervus elaphus; Bovidae, Caprinae: Capra pyrenaica, Rupicapra rupicapra; Equidae: Equus; Canidae: Canis Lupus y una categoría IND (Indeterminado), para ungulados sin atribución determinable específicamente por el momento (Fig. 2).

La matriz de datos de referencia del conjunto faunístico ofrece los recuentos del número de restos total (NRT), que incluye los no determinables (ND) y los determinables (NRD), el número de restos y fragmentos de mandíbulas (15) y su represen-

(15) Se han establecido unas categorías siguiendo el patrón más común de fracturación antrópica reconocido por varios autores (Altuna y Mariezkurrena 1985; Stiner 1994): 1- serie dental, 
tatividad en relación al NRT (número de restos total) del conjunto óseo conservado:

$$
\begin{aligned}
& \text { - NRT = } 8.038 \\
& \text { - NR mandíbulas = } 130(2 \%)
\end{aligned}
$$

Las unidades cuantitativas más básicas empleadas en este estudio han sido los estimadores de abundancia y otras unidades derivadas de estos. En este apartado presentamos los datos cuantitativos globales que caracterizan nuestra muestra (Tab. 2), y siempre que ha sido posible, se ha desglosado en taxones; los recuentos han resultado ser considerablemente bajos para muchos otros cálculos derivables.

\begin{tabular}{|l|r|r|r|}
\hline \multirow{2}{*}{ TAXÓN } & \multicolumn{3}{|c|}{ Mandíbula } \\
\cline { 2 - 4 } & NME & \multicolumn{1}{|c|}{ NMI } & NISP \\
\hline Cervus & 11 & 7 & 25 \\
\hline Capra & 5 & 4 & 5 \\
\hline Rupicapra & 9 & 5 & 14 \\
\hline Equus & 2 & 1 & 12 \\
\hline Canis lupus & 1 & 1 & 1 \\
\hline Ind & 9 & - & 73 \\
\hline
\end{tabular}

Tab. 2. Datos cuantitativos de abundancia.

\subsection{Carácter estacionario del yacimiento: perfiles de mortalidad}

A pesar de que contábamos con una muestra pequeña de series dentales, dentro de las 130 que conforman el total de fragmentos mandibulares seleccionados, se ha logrado establecer una edad aproximada en 42 restos. Conviene apuntar que los perfiles demográficos se han establecido a partir del Número de Restos, y no del Número Mínimo de Individuos o de Elementos, por ser significativamente muy bajos (Fig. 3).

La tabla que proponemos seguidamente, recoge las series dentales con edad relativa calculada especificada por taxones y la cohorte preestablecida a la que se han adscrito, usando como referente las tablas de erupción y desgaste ya explicitadas. No obstante, y como se podrá observar, algunas de las

\footnotetext{
que corresponde a la rama horizontal por encima del canal medular; se ha considerado la presencia de piezas dentarias o la existencia de los alveolos vacíos; 2- rama horizontal y gonion: la parte situada por debajo del canal medular; 3- parte anterior, corresponde a la zona de los incisivos y al diastema; 4- cóndilo mandibular, en la rama ascendente o zona articular; 5- apófisis o proceso coronoide, también en la rama ascendente y $\mathrm{C}$ - para hemimandíbulas completas (ninguna conservada).
}

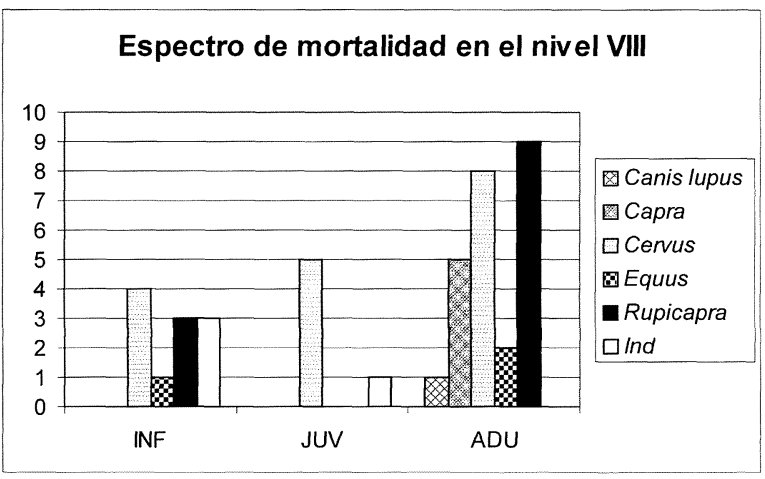

Fig. 3. Espectro de mortalidad en el nivel VII establecido a partir de mandíbulas.

\begin{tabular}{|l|c|c|c|}
\hline \multicolumn{1}{|c|}{ TAXÓN } & EDAD & TOTAL & COHORTE \\
\hline Equus & 8 meses-1 año & 1 & INF \\
\hline Rupicapra & $>2$ meses & 1 & INF \\
\hline Cervus & $10-15$ meses & 1 & JUV \\
\hline Cervus & $19-21$ meses & 1 & JUV \\
\hline Rupicapra & $>4$ meses & 1 & JUV \\
\hline Rupicapra & $4-17$ meses & 1 & JUV \\
\hline Cervus & $10-20$ meses & 1 & JUV \\
\hline Cervus & $18-24$ meses & 1 & JUV \\
\hline Cervus & $17-22$ meses & 2 & JUV \\
\hline Cervus & $3-5$ años & 3 & ADU \\
\hline Capra & $3-6$ años & 1 & ADU \\
\hline Capra & $4-6$ años & 1 & ADU \\
\hline Cervus & $5-7$ años & 1 & ADU \\
\hline Capra & $6-8$ años & 1 & ADU \\
\hline Cervus & $6-9$ años & 1 & ADU \\
\hline Cervus & $7-9$ años & 1 & ADU \\
\hline Cervus & $7-12$ años & 2 & ADU \\
\hline Capra & $>8$ años & 2 & ADU \\
\hline Equus & $8-12$ años & 1 & ADU \\
\hline Equus & $\wedge 10$ años & 1 & ADU \\
\hline Rupicapra & $>28-30$ meses & 5 & ADU \\
\hline Cervus & $>15$ años & 1 & SEN \\
\hline
\end{tabular}

Tab. 3. Series dentales con edad relativa calculada probable: INF = Infantil; JUV = Juvenil; ADU = adulto; SEN $=$ senil.

horquillas de edad calculadas, resultan demasiado amplias (Tab. 3).

Es de bastante relevancia extraer la frecuencia de inmaduros en cada nivel porque a partir de este porcentaje podemos aproximarnos a datos de estacionalidad probable. Para reconocer este porcentaje, hemos considerado conjuntamente a los infantiles y juveniles, frente a adultos y seniles. Para este conjunto óseo hemos obtenido un $40 \%$ a partir del elemento mandíbula (Tab. 4).

Intentaremos ahora extrapolar algun dato estacional a partir de lo expuesto hasta el momento. Disponemos para nuestro análisis de un 56\% de 


\begin{tabular}{|c|c|c|c|c|c|c|}
\hline Taxón & INF & JUV & ADU & SENIL & IND & TOTAL \\
\hline Cervus & 2 & 7 & 7 & 1 & 8 & 25 \\
\hline Capra & - & - & 5 & - & - & 5 \\
\hline Rupicapra & 1 & 2 & 9 & - & 2 & 14 \\
\hline Equus & 1 & - & 2 & - & 9 & 12 \\
\hline Canis lupus & - & - & $1 *$ & - & - & 1 \\
\hline Ind & 3 & 1 & - & - & 69 & 73 \\
\hline Total gen & 7 & 10 & 24 & & 88 & 130 \\
\hline
\end{tabular}

Tab. 4. Perfil de mortalidad en mandíbulas: INF = infantil; JUV = juvenil; ADU = adulto; IND = sin edad determinable.

* la edad de este espécimen (old) comprende las cohortes VIII-IX de desgaste en vista oclusal según Stiner (1994: 323).

fragmentos de mandíbulas de individuos sin edad determinable (IND); ello es debido a que pertenecen a otros fragmentos de mandíbula, excluyendo la rama horizontal con dentición conservada. A la vista de estos datos, hemos intentado averiguar algunos rasgos de estacionalidad a partir de las series dentarias con edad relativa aproximada de los individuos inmaduros. Partimos del hecho de que la serie es bastante pequeña e incompleta, pero trataremos de ajustarnos lo más posible a las características poblacionales y ecológicas de cada especie. Tenemos una muestra de 31 series de edad establecidas, respecto a un total de 130 fragmentos de mandíbulas muestreadas. Esto representa un 23\%, respecto del NISP total, pero si dejamos a un lado los adultos ( $\mathrm{n}=21+1$ senil), tenemos un total de 2 series de infantiles +8 series de juveniles determinadas. En total, un $n$ de 10, es decir, un 7\% sobre la muestra total (NISP=130). Parece que nuestras posibles determinaciones no serán por el momento, y a falta de más datos, demasiado concluyentes. Además habría que tener muy en cuenta que la débil presencia de inmaduros, infantiles y juveniles, quiza responda a problemas de conservación diferencial.

Con todo, trataremos de estimar de manera preliminar, el posible momento de muerte de alguno de los individuos representados en el conjunto, con edad calculada, recogidas en la tabla 5, ajustando y

\begin{tabular}{|l|l|c|c|l|}
\hline \multicolumn{1}{|c|}{$\mathbf{N}^{\mathbf{*}}$} & TAXÓN & EDAD & COHORTE & ESTACIONALIDAD \\
\hline CL0158M & Equus & $8-12$ meses & INF & fin inv-primavera \\
CL0097M & Rupicapra & $>2$ meses & INF & verano \\
CL0189M & Rupicapra & $>4$ meses & JUV & otoño \\
CL0072M & Rupicapra & $4-17$ meses & JUV & ? \\
CL0086M & Cervus & $10-15$ meses & JUV & verano \\
CL0136M & Cervus & $19-21$ meses & JUV & fin inv-primavera \\
CL0147M & Cervus & $17-22$ meses & JUV & fin inv-primavera \\
CL0149M & Cervus & $18-24$ meses & JUV & fin inv-primavera \\
CL0178M & Cervus & $10-20$ meses & JUV & abril-febrero? \\
CL0194M & Cervus & $17-22$ meses & JUV & fin inv-primavera \\
\hline
\end{tabular}

Tab. 5. Especímenes de edad aproximada calculada con estacionalidad probable.

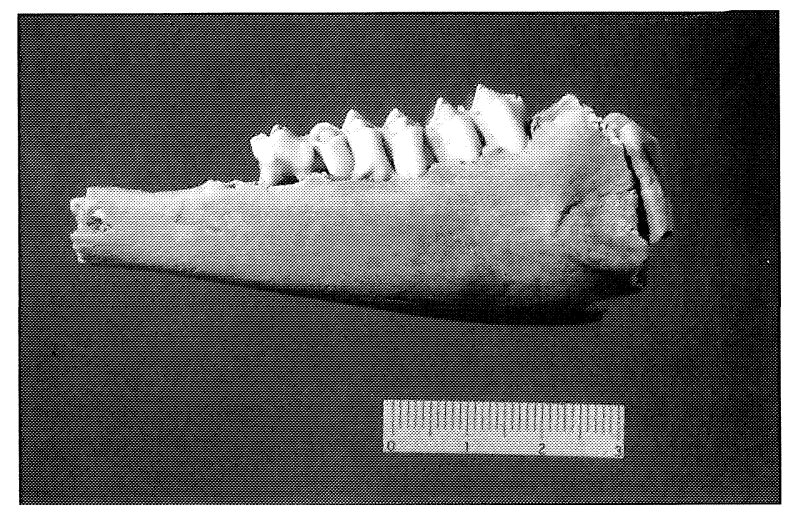

Lám. I. Hemimandíbula de Rupicapra. Individuo juvenil abatido aproximadamente en otoño.

siguiendo los datos de los ciclos reproductivos de cada especie de ungulado. Asumimos inicialmente que para los cérvidos el nacimiento se produce entre mayo y junio, para los cápridos, en junio, y para los équidos, entre los meses de abril, mayo y junio, aproximadamente, siempre que se estime que los ritmos biológicos son similares, o bastante aproximados, en los ungulados del Pleistoceno superior y en las especies actuales.

$\mathrm{El}$ individuo CL0158M probablemente muriera a finales del invierno o en primavera (entre enero y mayo); el CL0097M en el verano (agosto/septiembre); el CL0189M en octubre o noviembre (Lám. I); el CL0072M cuenta con unos márgenes demasiado amplios; el CL0086M, en el verano (abrilseptiembre); el CL0136M, a finales del invierno (febrero?); el CL0178M, tiene una horquilla temporal muy amplia, desde abril a febrero. Tanto el CL0147M como el CL0194M, habrían sido abatidos a finales del invierno o en primavera (noviembre a abril) (Lám. II). El CL0149M, lo estaría a fi-

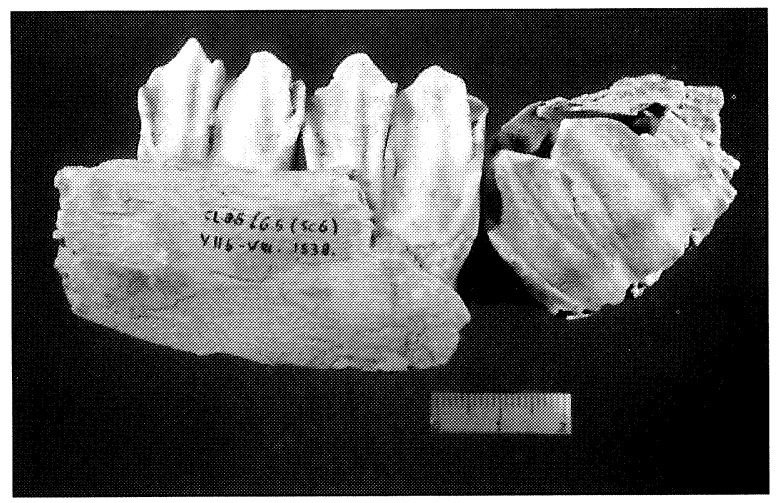

Lám. II. Hemimandíbula de Cervus. Individuo juvenil abatido probablemente a fines de invierno y primavera. 


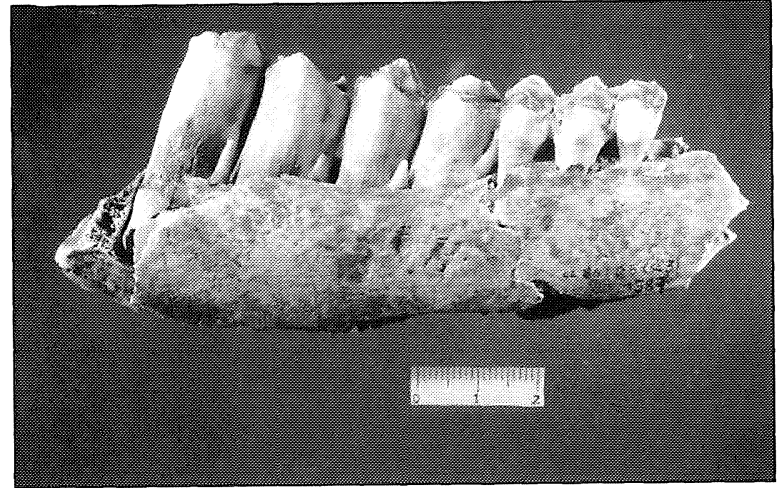

Lám. III. Hemimandíbula de Cervus. Individuo juvenil abatido probablemente a fines de invierno y primavera.

nal del invierno o en primavera (diciembre a junio) (Lam. III). Con todo, las apreciaciones son demasiado imprecisas y la horquilla temporal para precisar la época de muerte bastante prolongada en el tiempo.

Las consideraciones oportunas sobre la condición de los animales en estas épocas habrán de hacerse con cautela, porque desconocemos el sexo de los taxones por el momento y estamos valorando inicialmente en este estudio sólo a los individuos más jóvenes de la población muestreada en este nivel.

\subsection{Modificaciones de origen antrópico}

Las mandíbulas son poco apreciadas como hueso medular por su carácter de hueso voluminoso en relación con la cantidad de médula que produce, y porque su contenido en ácido oleico es bajo (25\%) frente a los altos valores de las extremidades (fémur distal $=51 \%$; metatarso distal $=73 \%$ ). Pero algunas características hacen de este elemento anatómico una parte muy útil como recurso de emergencia en las épocas más críticas: su proporción de contenido graso es más alto que la de las extremidades y es la última reserva de grasa en agotarse en el periodo de estrés biológico (Speth 1983: 168, 1987, 1989, 1990, 1991, 1992; Speth y Spielmann 1983).

Existen muchas formas de procesar este elemento anatómico para extraer todos sus nutrientes. $\mathrm{Al}-$ gunos investigadores recogen pruebas de este gesto en comunidades cazadoras recolectoras que permanecen en la actualidad (Binford 1978: 149-150; Enloe 1993). Además, sugiere que las mandíbulas, al igual que el esqueleto craneal, son transportadas al lugar de habitación más frecuentemente en la primavera, cuando la médula se ha agotado en los huesos largos.

Las hemimandíbulas analizadas en el Abri Flageolet I son fracturadas según una técnica que todavía hoy practican los esquimales (Delpech y Rigaud 1974: 48) consistente en realizar dos fracturas transversales, la primera en la parte anterior a la serie dental y la segunda en la zona posterior, quedando así aislada la parte mesial de la hemimandíbula, que a su vez se rompe longitudinalmente para abrir la cavidad medular. Algunos investigadores ya observaron los ritmos o, mejor dicho, los patrones de fracturación de mandíbulas en otros yacimientos como Erralla (Altuna y Mariezkurrena 1985) y La Riera (Altuna 1986).

La alta fragmentación de los huesos de Las Caldas sugiere que casi todas las especies acumuladas han sido manipuladas antrópicamente para extraer la máxima cantidad de alimento, una evidencia más del procesado de la médula. La mayor parte de nuestras reflexiones se centraron en la fracturación, tanto en su desarrollo general cuantitativo como en el cualitativo (Mateos 2002).

El análisis de restos intervenidos por acción humana (huellas de procesado), es decir, el estudio de las marcas de corte y otras del proceso de carnicería, junto a las evidencias de otras alteraciones óseas y trazas de carácter tafonómico, nos permiten establecer el porcentaje de fragmentados (23\%), de percutidos (50\%) y de corte (13\%) y el conjunto de intervención antrópica (Grado IA, tabla 6).

\begin{tabular}{|l|r|}
\hline \multicolumn{1}{|c|}{ Taxón } & \multicolumn{1}{c|}{ IA } \\
\hline Canis lupus & $100 \%$ \\
\hline Capra & $100 \%$ \\
\hline Cervus & $96 \%$ \\
\hline Equus & $83 \%$ \\
\hline Rupicapra & $28 \%$ \\
\hline Ind & $45 \%$ \\
\hline
\end{tabular}

Tab. 6. Índice de intervención antrópica (IA).

\section{CONCLUSIONES}

La valoración conjunta de lo hasta ahora expuesto nos permite comparar las variables explicitadas anteriormente como ejes de nuestro análisis (Tab. 7) para poder entrar a valorar las cuestiones relacionadas con la intervención antrópica y el con-

T. P., 59, n. ${ }^{\circ} 2,2002$ 


\begin{tabular}{|l|r|r|r|r|r|r|}
\hline \multicolumn{7}{|c|}{ Mandíbulas } \\
\hline Taxones & Cervus & Capra & Rupicapra & Equus & Canis lupus & Ind \\
\hline \%Inmaduros & 52 & 0 & 25 & 33 & 0 & 100 \\
\hline \%ragmentación & 36 & 20 & 28 & 25 & 0 & 35 \\
\hline \%Intervención & 96 & 100 & 28 & 83 & 100 & 45 \\
\hline
\end{tabular}

Tab. 7. Contraste específico de las variables señaladas en este análisis.

sumo efectuado por los grupos humanos que habitaron en el 13000 BP la Cueva de Las Caldas.

Lo que conocemos hasta el momento de la subsistencia de estos grupos es que estos cazadores se nos presentan como buenos conocedores del medio, que se adaptaron al entorno del valle y ocuparon la cueva al menos los 2/3 del año (Cazals y Mateos, e.p). No encontramos ningún indicador de estacionalidad evidente, al menos en la muestra analizada; por contra, las temporadas de caza quizá no fueran marcadamente estacionales sino que se distribuirían de forma prolongada en el transcurso del año. El perfil de mortalidad obtenido es de manera general no selectivo y quizá refleje una caza oportunista entre los individuos representados en el conjunto, cazado en las manadas disponibles próximas al yacimiento.

Los ritmos estacionales de actividad pueden también complementarse con otros datos y no sólo los dentarios (presencia de cuernas, sexo de los taxones por elementos determinantes de bimodalidad y dimorfismo sexual -cuernas, caninos, etc. $-\mathrm{y}$ variables osteométricas, DT max. húmero distal, DT max. metacarpo distal y DT max. calcáneo...), a la hora de establecer las tácticas de selección de individuos, tanto por edad como por sexo, y si estas preferencias se asocian a alguna captura intensiva. Como conclusión preliminar y a la espera de finalizar el estudio completo en curso, en principio parece una caza no selectiva a expensas de Cervus, Capra, Rupicapra y Equus, recursos animales de biotopos preferenciales cercanos al yacimiento: biotopos abiertos y de roquedo como espacios explotados. Restaría evaluar los datos de tecnología y tradiciones culturales de estos grupos para intentar aproximarnos a los modos de vida paleolíticos ampliando así nuestra idea sobre las gentes "magdalenienses".

Si valoramos los índices de consumo intensivo y la selección intencionada de estas piezas esqueléticas, no se puede asegurar completamente este tipo de estrategia dado que los elementos anatómicos mandibulares representan tan sólo un $2 \%$ en el NRT del conjunto conservado, aunque de hecho, ofrezcan unos altísimos porcentajes de antropización.

Nuestras reflexiones finales, y aún provisionales, no pueden dar una visión precisa de las estaciones de ocupación y actividades de subsistencia de estos grupos humanos, así el yacimiento deja abierta una prometedora perspectiva para los estudios de paleoeconomía en el sector más occidental del Cantábrico al final del Pleistoceno. Estas sociedades contaban sin duda con toda una serie de actividades organizadas ante las variaciones y presiones del entorno. Estas respuestas adaptativas y estrategias de subsistencia de planificación temporal intencionada o diferencial rigen la dinámica del grupo y forman parte de su sistema paleoeconómico.

\section{AGRADECIMIENTOS}

La realización de este trabajo ha sido posible gracias a una Beca FPI en el Dpto. de Prehistoria, Historia Antigua y Arqueología de la Universidad de Salamanca, y actualmente a una Beca de Investigación.

\section{BIBLIOGRAFÍA}

AITKEN, R. J. 1975: "Cementum layers and tooth wear as criteria for ageing Roe deer (Capreolus capreolus)". Journal Zool. Lond. 175,: 15-28.

ALTUNA, J. 1986: "The mammalian faunas from the prehistoric site of La Riera". En L.G. Straus y G.A. Clark (eds.): La Riera Cave. Stone age hunther-gatherer adpatations in northern Spain. Anthropological Research Papers. 36. Arizona,: 237-274.

ALTUNA, J. y MARIEZKURRENA, K. 1985: "Bases de subsistencia de los pobladores de Erralla: macromamíferos". Munibe XXXVII: 87-117.

BEASLEY, M. J.; BROWN, W. A. B. y LEGGE, A. J. 1992: "Incremental banding in dental cementum: methods of preparation for teeth from archaeological sites and for modern comparative specimens". International Journal of Osteoarchaeology 2: 37-50.

BILLAMBOZ, A. 1979: "Les vestiges en bois de cervides dans les gisements de l'époque holocene. Essai d'identification de la ramure et de ses differentes composantes". En H. Camps-Fabrer (ed.): L'industrie en os et en bois de cervidé. Néolithique et l'âge du Metaux. CNRS. Paris: 93-129.

BINFORD, L. R. 1978: Nunamiut Ethnoarchaeology. Academic Press. New York.

BLASCO SANCHO, M. F. 1995: Hombres, fieras y presas. Estudio arqueozoológico y tafonómico del yacimiento 
del Paleolítico Medio de la Cueva de Gabasa 1 (Huesca). Monografías Arqueológicas 38. Universidad de Zaragoza. Zaragoza.

- 1997: "In the pursuit of game: the mousterian cave site of Gabasa 1 in the Spanish Pyrenees". Journal of Anthropological Research 53: 177-217.

BOURQUE, B.J.; MORRIS, K. y SPIESS, A. 1978: “Determining the season of death of mammal teeth from archaeological sites: a new sectioning technique". Science 199: 530-531.

BROWN, W.A. y CHAPMAN, N.G. 1990: "The dentition of Fallow deer (Dama dama): a scoring scheme to assess age from wear of the permanent molariform teeth". Journal of Zoology 221: 659-682.

- 1991: "Age assesment of red deer (Cervus elaphus): from a scoring scheme based on radiographs of developing permanent molariform teeth". Journal of Zoology 225: 85-97.

BRUGAL, J.P. y DAVID, F. 1993: "Usure dentaire, courbe de mortalité et 'saisonnalité': les gisements du Paléolithique moyen à grands bovidés". En J. Desse y F. Audoin-Rouzeau (eds.): Exploitation des animaux sauvages à travers le temps. Ed. APDCA: 6377.

BRUGAL, J. P. ; DAVID, F. y FARIZY, C. 1994: "Quantification d'un assemblage osseux: paramètres et tableaux". En M.E. Patou-Mathis (ed.): Taphonomie/ Bone modification. CEDARC 9. Bélgica: 143-154.

BURKE, A. 1993: "Applied skeletochronology: a horse as human prey during the Pleniglacier in Southwestern France". En G. Larsen Peterkin, H.M. Bricker y P. Mellars (eds.): Hunting and animal exploitation in the later Palaeolithic and Mesolithic of Eurasia. Archaeological Papers of the American Anthropologist Association 4: 146-150.

BURKE, A. y CASTANET, J. 1995: "Histological observations of cementum growth in horse teeth and their application to Archaeology". Journal of Archaeological Science 22: 479-493.

CARTER, R.J. 1998: "Reassesment of seasonality at the early mesolithic site of Star Carr, Yorkshire based on radiographs of mandibular tooth development in Red deer (Cervus elaphus)". Journal of Archaeological Science 25: 851-856.

CASTAÑOS UGARTE, P. 1984: “Algunas observaciones acerca del Número de restos (NR), y del Número Mínimo de Individuos (NMI) en los estudios de Arqueozoología". Kobie XIV: 319-322.

CASTEEL, R.W. 1977: "Characterization of faunal assemblages and the Minimum number of individuals determined from paired elements: continuing problems in Archaeology". Journal of Archaeological Science 4: 125-134.

CAZALS, N. y MATEOS CACHORRO, A. (e.p.): "Modalités d'exploitation du milieu durant l'époque magdalénienne en Espagne cantabrique". Séance de la S.P.F.
Exploitation des milieux de montagne par les chasseurs-collecteurs. Grenoble 2001.

CORCHÓN RODRÍGUEZ, M. S. 1990: "La Cueva de Las Caldas (Priorio, Oviedo). Investigaciones efectuadas entre 1980 y 1986". Excavaciones Arqueológicas en Asturias, 1983-1986, 1:37-53. Servicio de Publicaciones del Principado de Asturias. Oviedo.

- 1992: "La Cueva de Las Caldas (Priorio, Oviedo) II. Investigaciones efectuadas entre 1987 y 1990". Excavaciones Arqueológicas en Asturias 1987-1990, 2: 33 47.

- 1995: "La Cueva de Las Caldas (Priorio, Oviedo) III. Resultados preliminares de las excavaciones (campañas 1991-1994)". Excavaciones Arqueológicas en Asturias, 1991-1994, 3: 45-59. Servicio de Publicaciones del Principado de Asturias. Oviedo.

- 1995b: "El Magdaleniense Medio. Nuevos datos sobre la ocupación de la Cornisa Cantábrica entre el 14000 y el 13000 BP". En A. Moure Romanillo y C. González Sainz (eds.): El final del Paleolítico cantábrico. Transformaciones ambientales y culturales durante el Tardiglaciar y comienzos del Holoceno en la región Cantábrica. Universidad de Cantabria. Cantabria: 119158.

- 1996: "Reflexiones acerca de la cronología del Magdaleniense cantábrico. Las dataciones $14 \mathrm{C}$ de la Cueva de Las Caldas (Asturias. España)". Zephyrus XLVIII1995: 3-19.

- 1999: "La Cueva de Las Caldas (Priorio, Oviedo) IV. Excavaciones 1995-1998". Excavaciones Arqueológicas en Asturias, 1995-1998. 4:43-57. Servicio de Publicaciones del Principado de Asturias. Oviedo.

- 2000: "Solutrense y Magdaleniense del oeste de la cornisa cantábrica: dataciones $14 \mathrm{C}$ (calibradas) y marco cronológico". Zephyrus LII-1999: 1-32.

CORCHÓN RODRÍGUEZ, S. y MATEOS CACHORRO, A. (e.p.): "Technologie et stratégies alimentaires des groupes humains du Cantabrique occidental: le Magdalénien supérieur de la grotte de Las Caldas (Priorio, Oviedo, Nord de l'Espagne)". En S. Costamagno y V. Laroulandi (eds.): Modes de vie au Magdalénien: apports de l'archaéozoologie. BAR International Series. Oxford.

CORCHÓN RODRÍGUEZ, M. S.; HOYOS, M.; SOTO, E. y MELÉNDEZ HEVIA, G. 1981: Cueva de Las Caldas, San Juan de Priorio (Oviedo). Excavaciones Arqueológicas en España 115. Ministerio de Cultura. Madrid.

COSTAMAGNO, S. 1999: Stratégies de chasse et fonction des sites au Magdalénien dans le Sud de la France. Préhistoire et Géologie du Quaternaire. Univ. de Bordeaux I: 495.

- 2000: "Stratégies d'approvisionnement et traitement des carcasses au Magdalénien: l'exemple de MoulinNeuf (Gironde)". Paleo 12: 77-95.

DAVID, F. y ENLOE, J.G. 1992: "Chasse saisonnière des

T. P., 59, n. ${ }^{\circ} 2,2002$ 
magdaléniens du Bassin Parisien”. Bulletin et Mémoires de la Société d'Anthropologie de Paris 4, n.s. 34: 167-174.

DAVIDSON, I. 1976: "Seasonality in Spain". Zephyrus XXVI/XXVII: 167-173.

- 1989: La economía del final del paleolítico en la España oriental. Servicio de Investigación Prehistórica, Serie de Trabajos Varios, Diputación Provincial de Valencia. Valencia.

DEBELJAK, I. 1996: “A simple préparation technique of Cave bear teeth for age determination by cementum increments". Revue de Paléobiologie 15 (1): 105-108.

DELPECH, F. y RIGAUD, J.Ph. 1974: "Étude de la fragmentation et de la répartition des restes osseux dans un niveau d'habitat paléolithique". En H. Camps-Fabrer (ed.): Premier Colloque International sur l'industrie de l'os dans la Préhistoire. Université de Provence. Aixen-Provence: 47-57.

DUCOS, P. 1975: "Analyse statistique des collections d'ossements d'animaux". En A.T. Clason (ed.): Archaeozoological Studies: 35-44.

- 1984: “La contribution de l'Archéozoologie à l'estimation des quantités de nourriture: évaluation du nombre initial d'individus". En J.Clutton-Brocks y C. Grigson (eds.): Animals and Archaeology 3: Early herders and theirflocks. BAR International Series 202. Oxford: 13-23.

ENLOE, J.G. 1993: "Ethnoarchaeology of marrow craking: implications for the recognition of prehistoric subsistence organization". En J. Hudson (ed.): From bones to behavior. Ethnoarchaeological and experimental contributions to the interpretation of faunal remains. Center for Archaeological Investigations. Southern Illinois University at Carbondale. Occasional Paper 21: 82-97.

- 1997: "Seasonality and age structure in remains of Rangifer tarandus: magdalenian hunting strategy at Verberie". Anthropozoologia 25-26: 95-102.

FORTEA, J.; CORCHÓN RODRÍGUEZ, M.S. ; GONZÁLEZ MORALES, M.; RODRÍGUEZ ASENSIO, A.; HOYOS, M.; LAVILLE, H.; DUPRÉ, M. y FERNÁNDEZ TRESGUERRES, J. 1990: "Travaux récents dans les vallées du Nalón et du Sella (Asturies)". En J. Clottes (ed.): L'Art des objects au Paléolithique. Actes du Colloque International de Foix-Le-Mas-d'Azil 1987. Tome 1: L'art mobilier et son contexte:219-244.

GAUTIER, A. 1984: "How do I count you, let me count the ways? Problems of archaeozoological quantification". En C. Grigson y J. Clutton-Brocks (eds.): Animals and Archaeology, 4.-Husbandry. British Archaeological Reports 227. Oxford: 237-251.

GIFFORD GONZÁLEZ, D. 1991a: "Bones are not enough: analogues, knowledge, and interpretative strategies in Zooarchaeology". Journal of Anthropological Archaeology 10: 215-254.

- 1991b: "Examining and refining the quadratic crown height method of age estimation". En M.C. Stiner (ed.):
Human Predators and Prey Mortality. Westview Press. Boulder Colorado: 41-78.

GORDON, B.C. 1988: Of men and reindeer herds in french magdalenian prehistory. BAR International Series 390. Oxford.

- 1993: "Archaeological tooth and bone seasonal increments: the need for standarized terms and techniques". Archaeozoologia V (2): 9-16.

GOSS, R. 1983: Deer antlers: regeneration, function and evolution. Academic Press.

GRANT, A. 1982: "The use of tooth wear as a guide to the age of domestic ungulates". En B. Wilson, C. Grigson y S. Payne (eds.): Ageing and sexing animal bones from archaeological sites. BAR British Series 109. Oxford: 91-108.

GRAYSON, D.K. 1979: “On the quantification of vertebrate faunas". Advances in archaeological method and theory 2: 199-237.

- 1984: Quantitative Zooarchaeology. Topics in the analysis of archaeological faunas. Academic Press. Orlando.

GRIGGO, C. y PUBERT, E. 1999: “Cémento-chonologie de quelques dents de bouquetin des Pyrénées (Capra hyrcus pyrenaica) provenant de la Grotte des Églises (Ussat, Ariège)". Paleo 11: 177-185.

GRUE, H. y JENSEN, B. 1979: "Review of the formation of incremental lines in tooth cementum of terrestial mammals". Danish Review of Game Biology 11(3): 148.

GUILLIEN, Y. y MARTIN, H.G. 1968: "Dentures de rennes et saisons de chasse: L'Abri aurignacien de La Quina". L'Anthropologie 72, 3-4: 337-348.

HILLSON, S. 1986: Teeth. Cambridge University Press.

HORTON, D.R. 1984: "Minimum numbers: a consideration". Journal of Archaeological Science 11: 255-271.

JONES, S. J. y BOYDE, A. 1974: "Coronal cementogenesis in the horse". Archs. oral Biol. 19: 605-614.

JORDÁ, F.; FORTEA, J. y CORCHÓN, S. 1982: "Nuevos datos sobre la edad del Solutrense y Magdaleniense medio cantábrico. Las fechas de C14 de la Cueva de Las Caldas (Oviedo, España)". Zephyrus XXXIV-XXXV: 13-16.

JULIEN, M. 1989: “Activités saisonnières et déplacements des magdaléniens dans le Bassin Parisien”. En J.Ph. Rigaud (ed.): Le Magdalénien en Europe: la structuration du Magdalénien. Actes du Colloque de Mayence 1987, $X I^{\circ}$ Congrès UISPP. ERAUL 38. Liège: 177-192.

KAY, M. 1974: "Dental annuli age determination on white-tailed deer from archaeological sites". Plains Anthropologists 19: 224-227.

KEISS, R. 1969: “Comparison of eruption-wear patterns and cementum annuli as age criteria in Elk". Journal of Wildlife Management 33: 175-180.

KLEIN, R.G. 1979: "Stone Age exploitation of animals in Southern Africa". American Scientist 67: 151-160.

- 1982: "Age (mortality) profiles as a means of distinguis- 
hing hunter species from scavenged ones in stone age archaeological sites". Paleobiology 8: 151-158.

KLEIN, R.G.; ALLWARDEN, K. y WOLF, C. 1983: "The calculation and interpretation of ungulate age profiles from dental crown heights". En G. Bailey (ed.): Hunter-gatherer economy in Prehistory. An european perspective. Cambridge University Press. Cambridge.

KLEIN, R.G.; WOLF, C.; FREEMAN, L.G. y ALLWARDEN, K. 1981: "The use of dental crown heights for constructing age profiles of Red deer and similar species in archaeological samples". Journal of Archaeological Science 8: 1-31.

KLEVEZAL, G. A. y PUCEK, Z. 1987: "Growth layers in tooth cement and dentine of European Bison and its hybrids with domestic cattle". Acta Theriologica 32 (9): 115-128.

KOIKE, H. y OHTAISHI, N. 1985: "Prehistoric hunting pressure estimated by the age composition of excavated Sika deer (Cervus nippon) using the annual layer of tooth cement". Journal of Archaeological Science 12: 443-456.

LE GALL, O. y MARTIN, H. 1996: "Pêches et chasses aux limites Landes/Pyrénées (quelques éléments de réflexion fondés sur les saisonnalités)". En H. Delporte y J. Clottes (eds.): Pyrénées préhistoriques: arts et sociétés. C.T.H.S.: 163-172.

LEVINE, M. A. 1982: "The use of crown height measurements and eruption wear sequences to age horse teeth". En B. Wilson, C. Grigson, y S. Payne, (eds.): Ageing and sexing animal bones from archaeological sites. BAR British Series 109. Oxford: 223-250.

- 1983: "Mortality models and the interpretation of horse population structure". En G. Bailey (ed.): Hunter-gatherer economy in Prehistory: an european perspective. Cambridge University Press. Cambridge:2346.

LIEBERMAN, D. E.; DEACON, T.W. y MEADOW, R.H. 1990: "Computer image enhancement and analysis of cementum increments as applied to teeth of Gazella gazella". Journal of Archaeological Science 17: 519533.

LIEBERMAN, D.E. y MEADOW, R.H. 1992: “The biology of cementum increments (with an archaeological application)". Mammal Rev. 22 (2): 57-77.

LOW, W.A. y COWAN, I.M. 1963: "Age determination of deer by annular structure of dental cementum". Journal of Wildlife Management 27 (3): 466-471.

LOWE, V.P. W. 1967: “Teeth as indicators of age with special reference to red deer (Cervus elaphus) of known age from Rhum". Journal Zool. Lond. 152: 137-153.

LUBINSKI, P.M. e.p.: "A comparison of methods for evaluating ungulate mortality distributions". En A. PikeTay (ed.): Assessing season of capture, age and sex of archaeofaunas. Archaeozoologia XI. Grenoble.

LUBINSKI, P.M. y O'BRIEN, C.J. 2001: “Observations on seasonality and mortality from a recent catastrophic death assemblage". Journal of Archaeological Science 28: 833-842. Cambridge.

LYMAN, R. L. 1987: "On the analysis of vertebrate mortality profiles: sample size, mortality type and hunting pressure". American Antiquity 52(1): 125-142.

- 1994a: "Quantitative units and terminology in Zooarchaeology". American Antiquity 59: 36-71.

- 1994b: Vertebrate Taphonomy. Cambridge University Press.

MARTIN, H. 1995: "La chasse au Post-glaciaire: les apports de la cémentochronologie, l'exemple de deux sites pyrénéens". En M. Otte (ed.): Nature, culture. Colloque de Liège. ERAULT 68. Liège: 273-288.

MARTIN, H. y Le GALL, O. 1989: "La faune mésolithique du gisement de la Doue (Corrèze). Implications palethnologiques". Archaeozoologica 3: 26-274.

MATEOS CACHORRO, A. 1999: "El consumo de grasa en el Paleolítico Superior. Implicaciones paleoeconómicas: nutrición y subsistencia". Espacio, Tiempo y.Forma, Serie I, Prehistoria y Arqueología 12: 59182.

- 2000: “Alimentación y consumo no cárnico en el Solutrense cantábrico: mandíbulas y falanges fracturadas intencionalmente en el nivel 9 de la Cueva de Las Caldas (Priorio, Oviedo)". Zephyrus LII-1999: 33-52.

- 2002: "Fracturation anthropique intentionelle sur mandibules et phalanges dans le niveau VIII de la Grotte de Las Caldas (Asturies, Espagne)". Préhistoire Européenne 16-17/2000-2001: 255-270.

MELTZER, D. V.; LEONARD, R.D. y STRASTTON, S.K. 1992: "The relationship between sample size and diversity in archaeological assemblages". Journal of Archaeological Science 19: 375-387.

MITCHELL, B. 1963: "Growth layers in dental cement for determining the age of Red deer (Cervus elaphus L.)". Journal of Animal Ecology 36 (2): 279-293.

MONKS, G.G. 1981: "Seasonality studies". Advances in archaeological method and theory 4: 177-240.

MONKS, G.G. y JOHNSTON, R. 1993: "Estimating season of death from growth increment data: a critical review". Archaeozoologia V (2): 17-40.

MORRISON, D. y WHITRIDGE, P. 1997: "Estimating the age and sex of caribou from mandibular measurements". Journal of Archaeological Science 24: 10931106.

NOVAKOWSKI, N.S. 1965: "Cemental deposition as an age criterion in Bison and the relation of incisor wear, eye-lens weight and dressed Bison carcass weigth to age". Canadian Journal of Zoology 43: 173-178.

OLSEN, S.L. 1989: "Solutré: a theoretical approach to the reconstruction of Upper Palaeolithic hunting strategies". Journal of Human Evolution 18: 295-327.

PAILHAUGUE, N. 1998a: "Dẹtermination de l'espèce et structure en âge dans une populations fossile du genre Rupicapra au Magdalénien pyrénéen”. Gibier Faune Sauvage 15 (3): 211-229.

T. P., 59, n. ${ }^{\circ} 2,2002$ 
- 1998b: "Faune et saisons d'occupation de la Salle Monique au Magdalénien pyrénéen Grotte de la Vache (Alliat, Ariège, France)". Quaternaire 9 (4): 385-400.

PÉREZ RIPOLL, M.; IBORRA ERES, P. y VILLAVERDE BONILLA, V. 2001: "Aplicación del estudio de la cementocronología a materiales de los niveles magdalenienses de la Cova de Les Cendres y la Cova del Parpalló: metodología y primeros resultados". Archaeofauna 10: 113-123.

PIKE-TAY, A. 1991a: "L'analyse du cement dentaire chez les cerfs: l'application en Préhistoire". Paleo 3: 149166.

- 1991b: Red deer hunting in the Upper Paleolithic of South-West France: a study in seasonality. BAR International Series 569. Oxford.

- 1995: "Variability and sinchronity of seasonal indicators in dental cementum microstructure of the Kaminuriak Rangifer population". Archaeofauna 4: 273-284.

- 1998: Seasonality of archaeofaunas in a multiscalar framework: a case study from Cantabrian Spain". En P. Rowley-Conwy (ed.): Animal Bones, Human Societies. Oxford, Owbow Books.

PIKE-TAY, A.; CABRERA VALDÉS, V. y BERNALDO DE QUIRÓS, F. 1999: "Seasonal variations of the middle-upper paleolithic transition at El Castillo, Cueva Morín and El Pendo (Cantabria, Spain)". Journal of Human Evolution 36: 283-317.

PIKE-TAY, A. y KNECHT, H. 1993 "Uncovering technological, organizational and seasonal strategies of paleolithic hunting: experimental contributions". En J. Hudson (ed.): From bones to behavior. Ethnoarchaeological and experimental contributions to the interpretation of faunal remains. Center for Archaeological Investigations. Southern Illinois University at Carbondale. Occasional Paper 21: 62-81.

POPLIN, F. 1976: “À propos du nombre de restes et du nombre d'individus dans les echantillons d'ossements". Cahiers du Centre de Recherches Préhistoriques I (5): 61-74.

- 1977: "Problèmes d'ostéologie quantitative relatifs à l'étude de l'écologie des hommes fossiles". En H. Laville y J. Renault-Miskovsk (eds.): Approche écologique de l'homme fossile: 63-68.

- 1981: "Un problème d'osteologie quantitative: calcul d'effectif initial d'après appariements. Generalisation aux autres types de remontages et d'autres materiels archeologiques". Revue d'Archéometrie 5: 159-165.

RICK, A. 1975: "Bird medullary bone: a sesonal dating technique for faunal analyst". Canadian Archaeological Association 7: 183-190.

SILVER, I.A. 1969: "The ageing of domestic animals". En D. Brothwell y B. Higgs (eds.): Science in Archaeology. Londres: 283-302.

SPETH, J.D. 1983: Bison kills and bone counts. University Chicago Press.
- 1987: "Early hominid subsistence strategies in seasonal habitats". Journal of Archaeological Science 14: 13-29.

- 1989: "Early hominid hunting and scavenging: the role of meat as an energy source". Journal of Human Evolution 18: 329-343.

- 1990: "Seasonality, resource stress and food sharing in so-called 'egalitarian' foraging societies". Journal of Anthropological Archaeology 9: 148-188.

- 1991: "Nutritional constraints and Late Glacial adaptative transformations: the importance of non-protein energy sources". En N. Barton, A.J. Roberts y D.A. Roe (eds.): The late Glacial in north-west Europe. C.B.A. London: 169-178.

- 1992: "Protein selection and avoidance strategies of contemporary and ancestral foragers: unresolved issues". En A. Whiten y E.M. Widdowson (eds.): Foraging strategies and natural diet of monkeys, apes and humans. Clarendon Press. Oxford: 265-270.

SPETH, J. D. y'SPIELMANN, K.A. 1983: "Energy source, protein metabolism and hunter-gatherer subsistence strategies". Journal of Anthropological Archaeology 2: $1-31$.

SPIESS, A. 1979: Reindeer and caribou hunters. An archaeological study. Academic Press. New York.

- 1995: "L'Abri Dufaure: étude de la saison d'habitation au moyen du cement dentaire". En L.G. Straus (ed.): Les derniers chasseurs de rennes du monde pyrénéen. L'Abri Dufaure: un gisement tardiglaciaire en Gascogne. CNRS: 213-217.

SPINAGE, C. A. 1976: "Incremental cementum lines in the teeth of tropical african mammals". Journal of Zoology 178: 117-131.

STALLIBRASS, S. 1982: "The use of cement layers for absolute ageing of mammalian teeth: a selective review of the literature with suggestion for further studies and alternative applications". En B. Wilson, C. Grigson y S. Payne (eds.): Ageing and sexing animal bones from archaeological sites. BAR British Series 109. Oxford: 109-126.

STINER, M.C. 1991: "The use of mortality pattern in archaeological studies of hominid predatory adaptations": Journal of Anthropological Archaeology 9:305351.

- 1994: Honor Among Thieves: A Zooarchaeological Study of Neandertal Ecology. Princeton University Press. Princeton, New Jersey.

VALENTE, M.J. 1997: “A quantificaçâo faunística: principais unidades, alguns parâmetros, regras e problemas". Estudos do Quaternario 1: 83-96.

VARIN (ed.) 1980: Chevreuil, cerf, sanglier. Les Editions de l'Orée. Bordeaux.

WEST, D. 1997: Hunting strategies in Central Europe during the last Glacial maximum. BAR International Series 672. Oxford. 


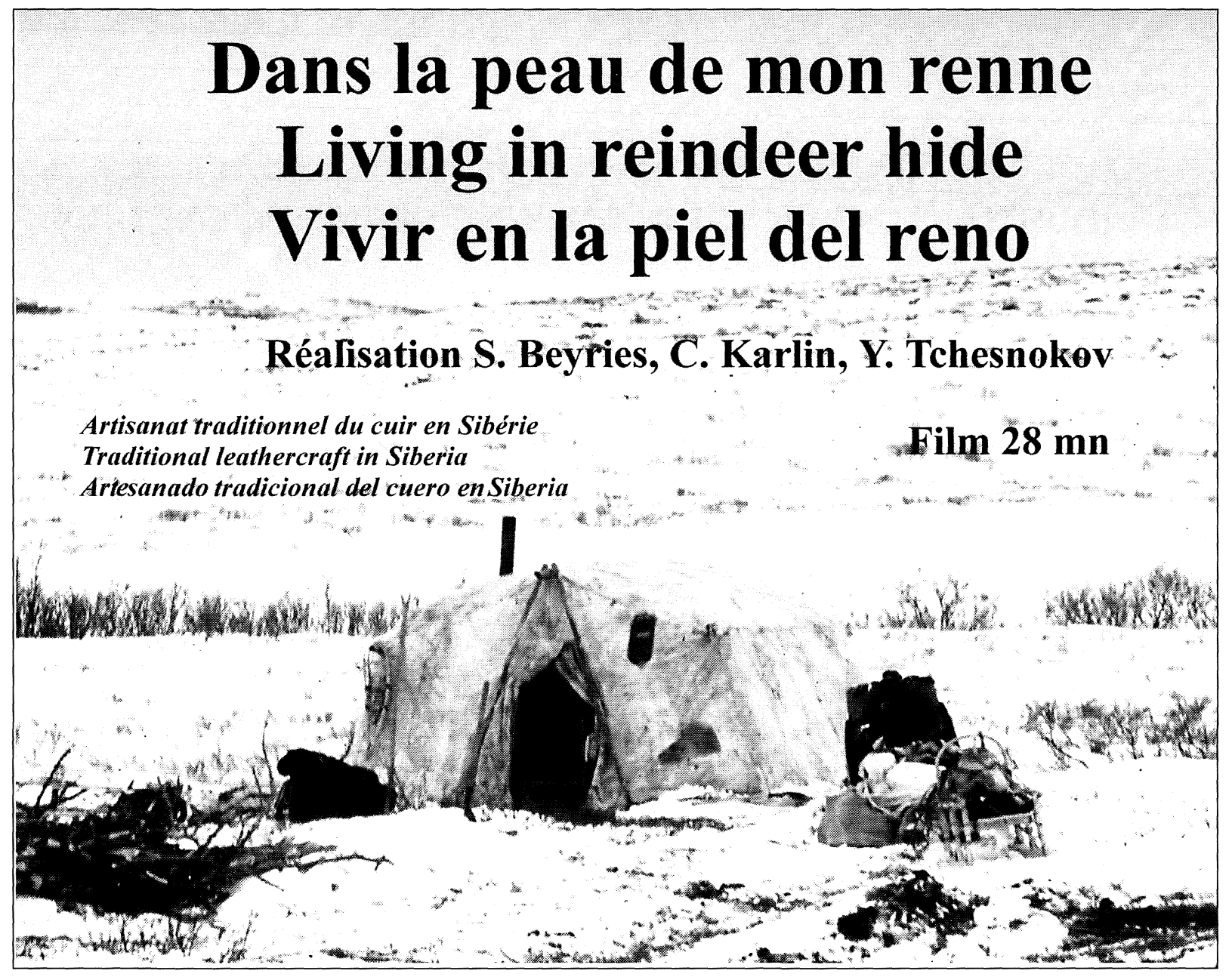

\section{BON DE COMMANDE}

Nom :

Prénom :

Adresse :

\begin{tabular}{|c|c|}
\hline $\begin{aligned} \text { Langue : } & \text { Français } \\
& \text { Anglais } \\
& \text { Espagnol }\end{aligned}$ & $\begin{array}{r}\text { Format : PAL } \\
\text { NTSC }\end{array}$ \\
\hline
\end{tabular}

Prix : 23€ (150 F) au bénéfice de l'école d'Atchaïvaïam

Etablir un Chèque à l'ordre de l'Institut Français pour la Recherche et

la Technologie Polaire (IFRTP)

l'adresser à Mission Ethno-Renne, CNRS, Cépam, Bâtiment 1,

250 rue A. Einstein, Sophia Antipolis, 06560 Valbonne France

\section{VIVIR EN LA PIEL DEL RENO}

El trabajo de las pieles es una actividad ampliamente compartida por todas las culturas, ya se trate de construir abrigos o elaborar vestidos o elementos de la vida cotidiana. Se transforma en una actividad vital en las regiones donde es necesario protegerse del frío y en donde casi ningún otro material se presta a las mismas transformaciones con las mismas cualidades.

Este vídeo constituye un ejemplo de la cadena operatoria del tratamiento de las pieles observado en el norte de Kamtchatka (Siberia oriental) en un grupo con una fuerte influencia tchouktche. Todo el proceso es seguido etapa por etapa y ha sido realizado en nuestra presencia por las mujeres del pueblo de Atchaïvaïam. Son, en efecto, las mujeres las que dominan todo el proceso de transformación, desde la fabricación de raspadores en piedra, todavía muy utilizados, el ablandamiento, el curtido, el teñido y hasta el cosido de las pieles. En la manufactura las mujeres utilizan los excrementos de sus renos, su propia orina y la corteza de aliso seleccionada de árboles que ellas consideran como de sexo "femenino". Un comentario en "off" explica el sentido de cada etapa, de cada momento del proceso.

Se trata de un documento muy valioso que, en el marco particularmente rico de una encuesta etnológica, puede ayudar a precisar las observaciones arqueológicas. Todos aquellos que se vean enfrentados a un posible trabajo sobre la manufactura de las pieles en un sitio arqueológico pueden encontrar en este vídeo de qué nutrir su reflexión. 